\title{
Disposition of Erlotinib and Its Metabolite OSI420 in a Patient with High Bilirubin Levels
}

\author{
M. Czejka ${ }^{a, b}$ \\ A. Sahmanovic ${ }^{a}$ \\ P. Buchner ${ }^{a, b}$ \\ T. Steininger ${ }^{c, d}$ \\ C. Dittrich ${ }^{c, d}$
}

${ }^{a}$ Department of Clinical Pharmacy and Diagnostics, University of Vienna, ${ }^{b}$ Austrian Society of Applied Pharmacokinetics, 'Applied Cancer Research, Institution for Translational Oncology Vienna (ACR-ITR VIEnna), and d Ludwig Boltzmann Institute for Applied Cancer Research (LBI-ACR VIEnna), 3rd Medical Department, Centre for Oncology and Haematology, Kaiser Franz Josef-Hospital, Vienna, Austria

\section{Key Words}

Erlotinib · OSI420 · Bilirubin · Pancreatic cancer · Drug monitoring $\cdot$ Pharmacokinetics

\begin{abstract}
Erlotinib is an oral epidermal growth factor receptor (EGFR) tyrosine kinase inhibitor approved for the treatment of non-small cell lung cancer and when combined with gemcitabine for pancreatic cancer. Dose reduction of erlotinib in patients with severe hepatic impairment has been established. We present the case of a male patient suffering from an adenocarcinoma of the pancreas with metastases in the liver and lung, whose disease progression led to highly elevated bilirubin levels of $>14 \mathrm{mg} / \mathrm{dl}$ accompanied by icterus and pruritus. Despite the known contraindication, the patient agreed to be treated with $150 \mathrm{mg}$ erlotinib p.o. per day. We performed therapeutic drug monitoring of erlotinib on day 1 after the first ingestion of erlotinib and then over a period of 19 days. One-compartment pharmacokinetics on day 1 were calculated, and, based on these data, a pharmacokinetic simulation for the following 19 days was run. On day 1 after the first erlotinib ingestion, plasma concentrations were identical to those described in the literature. On the following days, erlotinib plasma concentrations remained at a similar order of magnitude after daily ingestion. Compared with published data, OSI420 plasma concentrations were clearly higher from day 1 to 16. Due to disease progression, the last intake of erlotinib was on day 16, but plasma concentrations of the drug and metabolite increased excessively thereafter. The data
\end{abstract}


Czejka et al.: Disposition of Erlotinib and Its Metabolite OSI420 in a Patient with High Bilirubin Levels

give evidence that total bilirubin levels up to $14 \mathrm{mg} / \mathrm{dl}$ do not necessarily cause elevated plasma concentrations of erlotinib when given in doses of $150 \mathrm{mg}$ per day.

(c) 2013 S. Karger AG, Basel

\section{Background}

Erlotinib is an oral, reversible epidermal growth factor receptor (EGFR) tyrosine kinase inhibitor that has been approved for the treatment of non-small cell lung cancer [1] and combined with gemcitabine for pancreatic cancer [2]. In man, erlotinib is metabolised via the liver by CYP450s, primarily by CYP3A4 and to a lesser extent by CYP1A2, and by the pulmonary isoform CYP1A1.

Erlotinib is a moderate inhibitor of CYP3A4 and a strong inhibitor of UGT1A1 that is responsible for glucuronidation [3]. This inhibitory property has an impact on the level of the UGT1A1-mediated transport form of bilirubin, the corresponding glucuronide. Besides severe hepatic impairment, any inhibition of UGT1A1 by a drug would lead to a reduced elimination of bilirubin and cause accumulation in the body. Bilirubin levels greater than three times baseline normal bilirubin (the upper reference limit is $1.2 \mathrm{mg} / \mathrm{dl}$ ) are an expression of severe impairment of hepatic function.

A daily dose of $150 \mathrm{mg}$ erlotinib has been determined to be the recommended dose for single-agent use in phase II [4] and was used in all consecutive phase III trials [5-7]. In the last years, several cases of acute liver toxicity due to erlotinib have been reported [8-10], but no pharmacokinetic data have been evaluated.

\section{Patient and Methods}

\section{Patient}

In this case report, we describe the therapeutic drug monitoring (TDM) of erlotinib in a patient with abnormally high bilirubin levels with the aim to gain additional information on potentially necessary dose modifications or cessation of drug medication in patients with heavily impaired liver function.

The case of a 62-year-old male patient of $77 \mathrm{~kg}$ body weight with an adenocarcinoma of the pancreas and metastases in liver and lung is presented. From July 2009 to January 2010, seven cycles of combination chemotherapy consisting of gemcitabine and oxaliplatin were administered. The best response reached under this treatment was a partial response. Thereafter, treatment was discontinued because of hepatic progression of the disease. From March to April 2010, the patient was treated within the frame of a phase I study with an aurora-kinase B inhibitor. Because of progression in form of an increase of pre-existing, and appearance of new, hepatic and pulmonary metastases, the patient did no longer take part in the study. In April 2010, an icterus developed, necessitating an endoscopic retrograde cholangiopancreatography as well as the insertion of a stent to allow recanalisation and elimination of bile and, simultaneously, bilirubin. Nevertheless, despite the attempt of recanalisation of the bile duct, disease progression led to a further increase in bilirubin accompanied by icterus and pruritus.

After informing the patient in detail about the pros and cons of planning any further therapeutic step at all and after extensive discussion, erlotinib was used in the context of the now highly elevated bilirubin levels, with total bilirubin levels of $14.15 \mathrm{mg} / \mathrm{dl}$ (normal range $0.1-1.0 \mathrm{mg} / \mathrm{dl}$ ) and direct bilirubin levels of $11.32 \mathrm{mg} / \mathrm{dl}$ (normal range $0.1-0.25 \mathrm{mg} / \mathrm{dl}$ ), for 
which experience is lacking and intake of medication therefore not recommended. Written informed consent was obtained from the patient. The patient explicitly agreed to receive erlotinib $150 \mathrm{mg}$ daily for 16 days and additional accompanying blood drawings in order to allow elucidating the pharmacokinetics in this peculiar situation of impaired liver function. The investigation had been approved by the ethical committee.

\section{Analytical Assay}

Whole-blood samples of $5 \mathrm{ml}$ were drawn before treatment and 1, 2, 3, 4, 6, 8 and $24 \mathrm{~h}$ after erlotinib ingestion on day 1 . From day 2 to 19 , blood samples were collected regularly at $4 \mathrm{~h}$ after erlotinib ingestion. Erlotinib and OSI420 were isolated from blood matrix components by solid-phase extraction (Oasis HLB rp-18 cartridges) and quantitated by use of a selective and validated reversed-phase high-performance liquid chromatography assay.

\section{Pharmacokinetic Calculations}

For one-compartment pharmacokinetic analysis of erlotinib and non-compartment analysis of OSI420, the Kinetica $5 .{ }^{\circledR}$ software (InnaPhase Corp., USA) was used. The simulation of erlotinib plasma concentrations after multiple doses was performed by Phoenix WinNonlin ${ }^{\circledR} 6.1$ software (Certara, USA). Immediately after the first ingestion of erlotinib by the patient, a one-compartment analysis for erlotinib was run. Then, erlotinib plasma concentrations were simulated for the consecutive days 2-16 and compared with the data obtained from various blood samples of the same time interval from the patient.

\section{Results}

Over the investigated period, bilirubin exceeded $10 \mathrm{mg} / \mathrm{dl}$, whereas the transaminases $\gamma$-glutamyltransferase (GGT) and glutamic oxaloacetic transaminase (GOT) increased only slightly. Erlotinib was rapidly absorbed from the gut with an apparent half-life of absorption of $1.01 \mathrm{~h}$. Plasma concentrations showed a peak concentration $\left(\mathrm{c}_{\max }\right)$ of $2.05 \mu \mathrm{g} / \mathrm{ml}$, occurring $3.0 \mathrm{~h}$ after administration, and an area under the concentration time curve from 0 to $24 \mathrm{~h}\left(\mathrm{AUC}_{0-24 \mathrm{~h}}\right)$ of $29 \mu \mathrm{g} / \mathrm{ml} \cdot \mathrm{h}$ (non-compartment analysis). By one-compartment analysis, a very similar $\mathrm{c}_{\max }$ of $1.88 \mu \mathrm{g} / \mathrm{ml}$, occurring at $3.14 \mathrm{~h}$ (time of peak concentration; $t_{\max }$ ), was calculated. In the following days $2-16$, erlotinib plasma concentrations ranged from 0.6 to $1.75 \mu \mathrm{g} / \mathrm{ml}$ (fig. 1b).

The apparent half-life of formation of the active metabolite OSI 420 was about $5 \mathrm{~h}$, leading to plasma concentrations in the range from 0.08 to $0.17 \mu \mathrm{g} / \mathrm{ml}$. From day 16 (the day of the last erlotinib ingestion), plasma concentrations rapidly increased up to $0.64 \mu \mathrm{g} / \mathrm{ml}$, i.e. to about 3- to 6-fold the reported steady-state concentrations of $0.1-0.2 \mu \mathrm{g} / \mathrm{ml}$.

The detailed pharmacokinetic parameters of erlotinib and OSI 420 for day 1 are listed in table 1.

\section{Discussion}

Oral erlotinib is well absorbed with peak plasma levels ranging from 1.34 to $2.1 \mu \mathrm{g} / \mathrm{ml}$, occurring between 1.7 and $5.0 \mathrm{~h}$ after administration. The $\mathrm{AUC}_{0-24 \mathrm{~h}}$ ranges from 20 to 30 $\mu \mathrm{g} / \mathrm{ml} \cdot \mathrm{h}[11,12]$. The data presented for this patient are in accordance with these findings. To predict plasma data of erlotinib over the whole time period investigated, we performed a pharmacokinetic simulation of erlotinib plasma concentrations over 19 days, based on 
Czejka et al.: Disposition of Erlotinib and Its Metabolite OSI420 in a Patient with High Bilirubin Levels

results of a one-compartment analysis on day 1 . As can be seen in figure $1 \mathrm{~b}$, steady-state levels were reached after the 5 th ingestion of erlotinib, leading to a fluctuation with a through concentration ( $C_{\text {through}}$ ) of about $1.0 \mu \mathrm{g} / \mathrm{ml}$ and a $c_{\max }$ of about $2.8 \mu \mathrm{g} / \mathrm{ml}$. Observed plasma concentrations of the patient from day 2 to 19 are shown as circles; although being rather low, they do not differ from data in the literature $[13,14]$. Plasma cthrough of erlotinib exceeded the $0.5 \mu \mathrm{g} / \mathrm{ml}$ that are required for adequate tyrosine kinase inhibition [4]. After the last erlotinib ingestion on day 16 (arrow in fig. 1b), the simulation curve rapidly drops to about $0.2 \mu \mathrm{g} / \mathrm{ml}$ according to the pharmacokinetic compartment model. However, plasma concentrations in this patient excessively increased, although further erlotinib ingestion had been abandoned.

On the first day, the plasma concentrations of the metabolite OSI420 were in the same order of magnitude as described in the literature $[11,12]$. Compared to previous investigations, on the following days, OSI420 concentrations were higher over the whole investigated time period [15]. Inhibition of UGT1A1 by erlotinib could decrease the elimination rate of bilirubin-glucuronide and, as a consequence, cause an accumulation of non-conjugated bilirubin in the blood. Bilirubin levels were high from the beginning but of a similar order of magnitude from day 1 to 18 . Such high bilirubin concentrations may lead to abnormal plasma concentrations of erlotinib and OSI 420 when compared to patients with normal low bilirubin levels. A decreased plasma protein concentration may have a severe impact on the disposition of a usually highly protein-bound drug such as erlotinib (>85\%). As a consequence, the free and pharmacologic active amount of the drug in the blood increases and can lead to undesired side effects.

From day 16 (the day of the last erlotinib ingestion), erlotinib and OSI420 plasma concentrations increased excessively. This increase of OSI420 plasma concentrations can be explained either by a higher activity of the erlotinib metabolising enzymes CYP3A4 and CYP1A2 or by decreasing elimination processes. On the contrary, for increasing plasma concentrations of erlotinib, either a lower activity of CYP3A4 and CYP1A2 or reduced elimination processes may be responsible. The altered elimination process as a common denominator accompanied by increased plasma concentrations reflects the development of multiple organ failure, visualised by an altered volume of distribution (Vd) and total body clearance $\left(\mathrm{Cl}_{\text {tot }}\right)$ of erlotinib in the patient due to progressive disease with the patient passing away on day 19 after the first ingestion of erlotinib.

The prescribing information of the erlotinib supplier contains a warning concerning 'patients with hepatic impairment' stating that the dosing should be interrupted or discontinued if changes in liver function are severe such as doubling of total bilirubin and/or tripling of transaminases [13]. According to our data, this warning cannot be sustained or generalised for each patient with hepatic impairment. TDM could serve as a useful tool for a rational dose adaptation or interruption of therapy.

TDM of erlotinib has been discussed by Gao et al. [14] because the drug is administered at a fixed flat dose. Monitoring of erlotinib plasma concentrations on the first day of ingestion might be useful to decide whether a dose adaptation of erlotinib is necessary or not. Alternatively, the quantification of erlotinib through plasma values could be performed after repeated doses. For this purpose, less plasma samples are necessary compared to pharmacokinetic analysis on the day of first erlotinib ingestion.

The extrapolation of our data resulting from a single patient to other cases may be limited regarding their generalisability, but they represent successful drug monitoring of erlotinib in a patient with hepatic dysfunction. The data give evidence of plasma concentrations over the threshold of $0.5 \mu \mathrm{g} / \mathrm{ml}$ for tyrosine kinase inhibition by erlotinib, but these erlotinib concentrations were unexpectedly not abnormally high despite of the liver 


\begin{tabular}{l|l}
\hline DOI: $10.1159 / 000357211$ & $\begin{array}{l}\text { C 2013 S. Karger AG, Basel } \\
\text { www.karger.com/cro }\end{array}$ \\
\hline
\end{tabular}

Czejka et al.: Disposition of Erlotinib and Its Metabolite OSI420 in a Patient with High Bilirubin Levels

dysfunction. Further drug monitoring studies with erlotinib in compromised metabolic situations should be performed to establish proper dosing guidelines for erlotinib in patients with hepatic failure.

\section{Disclosure Statement}

C.D. has received honoraria from Roche Austria for consulting. The research institute directed by C.D. has received unrestricted research grants from Roche Austria. The Austrian Society of Applied Pharmacokinetics has received honoraria for pharmacokinetic consulting from Roche Austria. T.S., P.B., and A.S. have no conflict of interest.

\section{References}

1 Shepperd FA, Rodrigues Pereira J, Ciuleanu T, Tan EH, Hirsh V, Thongprasert S, Campos D, Maoleekoonpiroj S, Smylie M, Martins R, van Kooten M, Dediu M, Findlay B, Tu D, Johnston D, Bezjak A, Clark G, Santabárbara P, Seymour L: Erlotinib in previously treated non-small cell lung cancer. N Engl J Med 2005;353:123-132.

2 Moore MJ, Goldstein D, Hamm J, Figer A, Hecht JR, Gallinger S, Au HJ, Murawa P, Walde D, Wolff RA, Campos D, Lim R, Ding K, Clark G, Voskoglou-Nomikos T, Ptasynski M, Parulekar W: Erlotinib plus gemcitabine compared with gemcitabine alone in patients with advanced pancreatic cancer: a phase III trial of the National Cancer Institute of Canada Clinical Trials Group. J Clin Oncol 2007;25:1960-1966.

-3 Liu Y, Ramirez J, House L, Ratain M: Comparison of drug-drug interactions potential of erlotinib and gefitinib via inhibition of UDP-glucuronosyltransferase. Drug Metab Disp 2010;38:32-39.

4 Hidalgo M, Siu LL, Nemunitis J, Rizzo J, Hammond LA, Takimoto C, et al: Phase I and pharmacologic study of OSI-774, an epidermal growth factor receptor tyrosine kinase inhibitor, in patients with advanced solid malignancies. J Clin Oncol 2001;19:3267-3279.

-5 Cappuzzo F, Ciuleanu T, Stelmakh L, Cicenas S, Szczesna A, Juhasz E, Esteban E, Molinier O, Brugger W, Melezínek I, Klingelschmitt G, Klughammer B: Erlotinib as maintenance treatment in advanced non-smallcell lung cancer: a multicentre, randomised, placebo-controlled phase 3 study. Lancet Oncol 2010;11:521529.

-6 Zouh C, Wu YL, Gongyan CG, Wang C, Chen G, Feng J, et al: Erlotinib versus chemotherapy as first-line treatment for patients with advanced EGFR mutation-positive non-small-cell lung cancer (OPTIMAL, CTONG-0802): a multicentre, open-label, randomised, phase 3 study. Lancet Oncol 2011;12:735-742.

-7 Rosell R, Carcereny E, Gervais R Vergnenegre A, Massuti B, Felip E, et al: Erlotinib versus standard chemotherapy as first-line treatment for European patients with advanced EGFR mutation-positive nonsmall-cell lung cancer (EURTAC): a multicentre, open-label, randomised phase 3 trial. Lancet Oncol 2012;13:239-246.

8 Ramanarayanan J, Scarpace SL: Acute drug induced hepatitis due to erlotinib. J Pancreas 2007;8:39-43.

9 Saif MW: Erlotinib-induced acute hepatitis in a patient with pancreatic cancer. Clin Adv Hematol Oncol 2008;6:191-199.

10 Liu W, Markauer FL, Qamar AA, Janne PA, Odze RD: Fulminant hepatic failure secondary to erlotinib. Clin Gastroenterol Hepatol 2007;5:917-920.

-11 Tran HT, Zinner RG, Blumenschein R, Oh JW, Papadimitrakopoulou VA, Kim ES, Lu C, Malik M, Lum BL, Herbst RS: Pharmacokinetic study of the phase III, randomized, double blind, multicenter trial of paclitaxel and carboplatin combined with erlotinib or placebo in patients with advanced non-small cell lung cancer. Invest New Drugs 2011;29:499-505.

12 Yamamoto N, Horiike A, Fujisaka Y, Murakami H, Shimoyama T, Yamada Y, Tamura T: Phase I dose finding and pharmacokinetic study of the epidermal growth factor receptor tyrosine kinase inhibitor Ro8231 (erlotinib) in Japanese patients with solid tumors. Cancer Chemother Pharmacol 2008;61:489-496.

13 RxList. The Internet Drug Index. http://www.tarceva.com/patient/.

14 Gao B, Yeap S, Clements A, Balakrishnar B, Wong M, Gurney H: Evidence for therapeutic drug monitoring of targeted anticancer therapies. J Clin Oncol 2012;30:4017-4025.

15 Czejka M, Sahmanovic A, Buchner P, Terkola R, Steininger T, Dittrich CH: Clinical pharmacokinetics of erlotinib in advanced pancreatic cancer patients after single and multiple dose. Ann Oncol 2011;22(suppl 5):v58-v59, abstract P-0128. 
Czejka et al.: Disposition of Erlotinib and Its Metabolite OSI420 in a Patient with High Bilirubin Levels

Table 1. One-compartment pharmacokinetic parameters for erlotinib and non-compartment pharmacokinetic parameters for OSI420 after the first ingestion of $150 \mathrm{mg}$ erlotinib on day 1

\begin{tabular}{lcl}
\hline Pharmacokinetic parameter & Erlotinib (1CA) & OSI420 (NCA) \\
\hline $\mathrm{t}_{1 / 2}$ abs, h & 1.01 & not calculated \\
$\mathrm{t}_{1 / 2}$ formation, $\mathrm{h}$ & not calculated & 5.10 \\
$\mathrm{C}_{\max }, \mu \mathrm{g} / \mathrm{ml}$ (observed) & 2.05 & 0.17 \\
$\mathrm{C}_{\max }, \mu \mathrm{g} / \mathrm{ml}$ (calculated) & 1.88 & not calculated \\
$\mathrm{t}_{\max }, \mathrm{h}(\mathrm{observed})$ & 3.00 & 4.2 \\
$\mathrm{t}_{\max }, \mathrm{h}($ calculated) & 3.14 & not calculated \\
$\mathrm{AUC}_{0-24} \mathrm{~h}, \mu \mathrm{g} / \mathrm{ml} \cdot \mathrm{h}$ & 28.59 & 2.55 \\
$\mathrm{t}_{1 / 2} \mathrm{el}, \mathrm{h}$ & 14.71 & not calculated \\
Cl$_{\text {tot }}, \mathrm{l} / \mathrm{h}$ & 3.28 & not calculated \\
Volume of distribution, $\mathrm{l}$ & 72.0 & not calculated \\
\hline
\end{tabular}

$1 \mathrm{CA}=$ One-compartment pharmacokinetic parameters; NCA = noncompartment pharmacokinetic parameters; $\mathrm{t}_{1 / 2} \mathrm{abs}=$ absorption halflife; $\mathrm{t}_{1 / 2}$ formation $=$ apparent formation half-life; $\mathrm{t}_{1 / 2 \mathrm{el}} \mathrm{l}=$ elimination half-life. 
Czejka et al.: Disposition of Erlotinib and Its Metabolite OSI420 in a Patient with High Bilirubin Levels
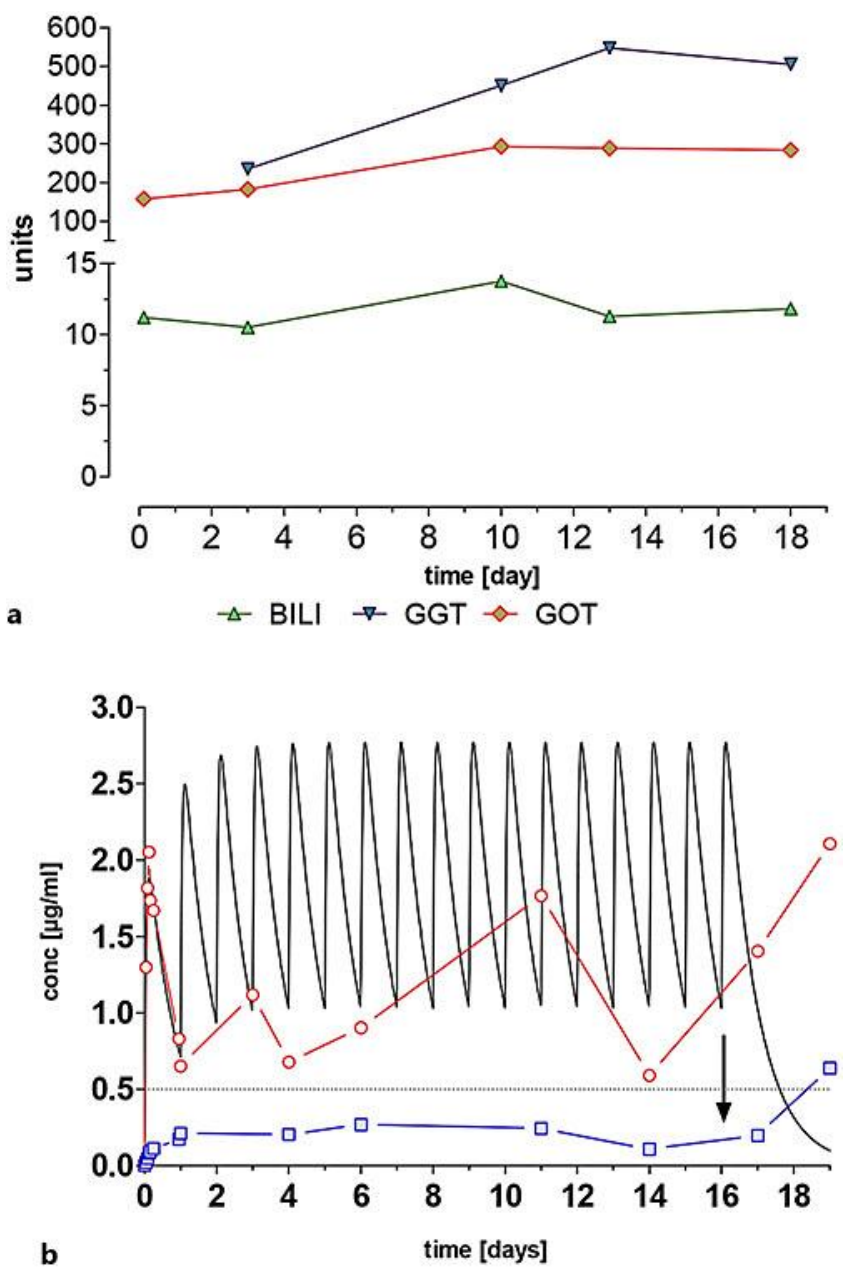

Fig. 1. a Course of laboratory parameters. b Observed plasma concentrations for erlotinib (circles) and OSI420 (squares) and simulated concentration time curve for erlotinib. The arrow indicates the time of the last erlotinib ingestion and the dashed line represents the required minimum $c_{\text {through }}$ of erlotinib for tyrosine kinase inhibition. BILI = Bilirubin. 